\title{
Health benefits of low glycaemic index foods, such as pulses, in diabetic patients and healthy individuals
}

\author{
S. W. Rizkalla, F. Bellisle and G. Slama* \\ Department of Diabetes, INSERM U341 and Assistance Publique, Hôtel-Dieu, 1, Place du Parvis Notre-Dame, \\ 75004 Paris, France
}

\begin{abstract}
The present paper covers the health benefits of low glycaemic index foods, such as pulses. Nutritional factors potentially play a crucial role in health and disease. A low-fat, high-carbohydrate diet is often recommended as a part of a healthy life-style. Historical works have shown that carbohydrate foods differ in their ability to affect post-ingestive glycaemia. The glycaemic index concept allows a ranking of carbohydrate-rich foods in terms of their blood glucose raising potential. Pulses are foods with very low glycaemic index values. Numerous studies have documented the health benefits that can be obtained by selecting foods of low glycaemic index. These benefits are of crucial importance in the dietary treatment of diabetes mellitus: glycaemic control is improved as well as several metabolic parameters, such as blood lipids. The results of human studies have been confirmed by animal experiments in the field of diabetes. Diets with low glycaemic index value improve the prevention of coronary heart disease in diabetic and healthy subjects. In obese or overweight individuals, low-glycaemic index meals increase satiety and facilitate the control of food intake. Selecting low glycaemic index foods has also demonstrated benefits for healthy persons in terms of post-prandial glucose and lipid metabolism. Several public health organizations have recently integrated consideration of the glycaemic index in their nutritional recommendations for patients with metabolic diseases and for the general population.
\end{abstract}

Glycaemic index: Pulses: Glycaemic control

\section{Introduction}

In industrialized societies as well as in developing countries, the prevalence of diabetes, obesity, and cardiovascular diseases (CVD) is increasing rapidly, especially in young individuals. Nutrition is suspected to play a decisive role in the increasing burden of these chronic conditions. Nutritional factors might also potentially exert a positive impact in the prevention and treatment of chronic disease. Several hypotheses suggesting such a nutritional role have been proposed in recent years. In particular, it has been proposed that the hyperglycaemia and/or hyperinsulinaemia that follows food intake could be a risk factor for the development of various metabolic pathologies. This is the case in poorly controlled diabetic patients, but perhaps also in healthy individuals (Feskens \& Kromhout, 1989; Salmeron et al. 1997). According to this hypothesis, it could be helpful to diminish the amplitude and the duration of post-prandial hyperglycaemia and/or the subsequent hyperinsulinaemia.
Some carbohydrate (CHO)-rich foods induce less postingestive hyperglycaemia-hyperinsulinaemia than others (Crapo et al. 1977; Bornet et al. 1987; Lang et al. 1999). In consequence, selecting the right kind of $\mathrm{CHO}$ foods could actually represent part of a strategy in the prevention and treatment of chronic metabolic disorders (Diabetes and Nutrition Study Group of the European Association for the Study of Diabetes, 1995; Food and Agriculture Organization/World Health Organization, 1998).

The glycaemic index (GI) refers to the blood glucose raising potential of carbohydrate $(\mathrm{CHO})$ foods (Wolever et al. 1991). The GI allows a classification of foods based on the post-prandial blood glucose response compared with a reference food. Pulses are foods with interestingly low GI, since the lowest glycaemic responses for starchy foods have been reported after consumption of dried legumes (Jenkins et al. 1981b, 1983; Bornet et al. 1997). It has been suggested in the past 20 years that deliberate selection of starches with low GI could potentially contribute to significant improvement of the conditions

Abbreviations: CHO, carbohydrate; CVD, cardiovascular disease; GI, glycaemic index; GL, glycaemic load; Hb A $1 \mathrm{c}$, glycosylated haemoglobin; IAUC, incremental area under the curve; IDDM, insulin-dependent diabetes mellitus; NEFA, non-esterified fatty acid; NIDDM, non-insulin-dependent diabetes mellitus; RR, relative risk; TG, triacylglycerol.

* Corresponding author: Professor Gerard Slama, tel +33 1423483 99, email gerard.slama@htd.ap-hop-paris.fr 
associated with poor glycaemic control (Brand-Miller, 1994). This may well not be the case in CHO foods with a low GI that are too rich in fat and/or fructose. Likewise, evidence supports the notion that selecting foods with low GI could improve numerous physical functions in healthy as well as diseased individuals.

\section{Historical development of the notion of glycaemic index}

The notion that $\mathrm{CHO}$ foods could induce different postingestion glycaemic responses for identical amounts of CHO was developed in the mid 1970s (Spaethe et al. 1972; Crapo et al. 1977; Jenkins et al. 1977). The importance of differing rates of digestion and rate of glucose absorption was recognized and research was devoted to documenting differences between $\mathrm{CHO}$ foods systematically (Jenkins et al. 1981a; Bornet et al. 1989, 1990; Lang et al. 1999).

The GI concept was initially proposed in 1981 (Jenkins et al. 1981a). The GI is a value that describes the rise in blood glucose observed following the intake of $\mathrm{CHO}$ foods, compared to the hyperglycaemia induced by the intake of an equivalent load of a standard $\mathrm{CHO}$ food. The GI of a given food is defined as the incremental area under the blood glucose response curve (IAUC) after intake of a $50 \mathrm{~g} \mathrm{CHO}$ portion of the food, expressed as a percentage of the IAUC following the intake of $50 \mathrm{~g}$ $\mathrm{CHO}$ from the standard (glucose or bread) by the same individual (Food and Agriculture Organization/World Health Organization, 1998). Fig. 1 presents typical glucose
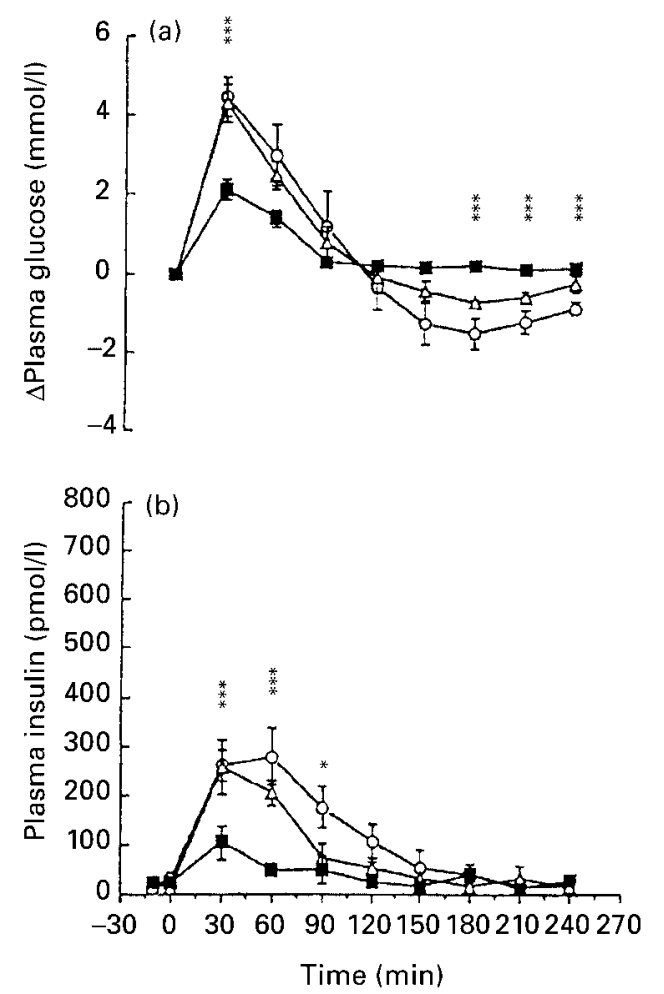

Fig. 1. Plasma glucose (a) and insulin (b) responses to the same quantity of three oral carbohydrate loads: mung bean starch ( $\boldsymbol{\square})$, maize starch $(\triangle)$ and glucose $(O) .{ }^{\star} P<0.05$, ${ }^{* \star *} P<0.005$. (From Lang et al. 1999.) and insulin responses following the ingestion of three carbohydrate sources (glucose, maize starch, mung bean starch) for post-prandial glucose and insulin (Lang et al. 1999).

In 1995, Foster-Powell and Brand-Miller published the first International Table of Glycaemic Index. This table has recently been updated (Foster-Powell et al. 2002).

\section{Pulses, a low glycaemic index food}

Legumes were identified as low GI foods more than 20 years ago (Jenkins et al. 1981b, 1983; Thorne et al. 1983). Fig. 2 lists the GI of three pulses and other types of foods (after Bornet et al. 1997). In healthy rats, the validity of the glycaemic index notion has been confirmed (LererMetzger et al. 1996). Kabir et al. (1998a) demonstrated that when starches with different amylose:amylopectin ratios (waxy cornstarch, 0.5:99.5\%; mung beans, 32:68\%) were incorporated into a mixed meal, the meal with the high amylopectin starch (waxy cornstarch) showed a higher glycaemic response than that of the low amylopectin starch (mung beans).

\section{Low glycaemic index foods, such as pulses, and glycaemic control in type 1 diabetes}

Variations of the GI of the diet were studied in 2810 European outpatients with type 1 diabetes mellitus (Toeller et al. 1996; Buyken et al. 2001). Possible relations to glycosylated haemoglobin $\left(\mathrm{Hb} \mathrm{A_{1c }}\right)$ and serum lipid concentrations were investigated. The GI was calculated from a $3 \mathrm{~d}$ dietary record obtained from participants in the European patients with Type 1 diabetes (EURODIAB) Complications Study, an epidemiological European Union Project including 31 centres throughout Europe. The GI of patients' diets was positively correlated with the level of $\mathrm{Hb} \mathrm{A}_{1 \mathrm{c}}$. In patients from southern Europe, with the lowest quartile GI values, the $\mathrm{Hb} \mathrm{A} \mathrm{A}_{1 \mathrm{c}}$ was $11 \%$ lower than in patients with the highest quartile. In other parts of Europe, the difference between extreme quartiles was $6 \%$. Among serum lipids, only HDL-cholesterol was independently related to the GI. This large European study confirmed that in outpatients with type 1 diabetes, a low dietary GI is related to low $\mathrm{Hb}$ $\mathrm{A}_{1 \mathrm{c}}$, independently of fibre intake.

In insulin-dependent diabetes mellitus (IDDM) patients, a low-GI diet was found to induce a small but significant decrease in glucose profile, with plasma glucose within the target range for optimal metabolic control (Lafrance et al. 1998). A decrease in insulin requirements was also found in another group of IDDM patients (Fontvielle et al. 1988). In a mixed group of both non-insulindependent diabetes mellitus (NIDDM) and IDDM patients, Fontvieille et al. (1992) demonstrated a decrease in fructosamine and triacylglycerols after a 5-week low-GI diet. A similar study by Calle-Pascual et al. (1988) failed to find any beneficial effect for such a diet.

\section{Low glycaemic index foods, such as pulses, and glycaemic control in type 2 diabetes}

Interest in the use of low-GI foods in type 2 diabetes has 


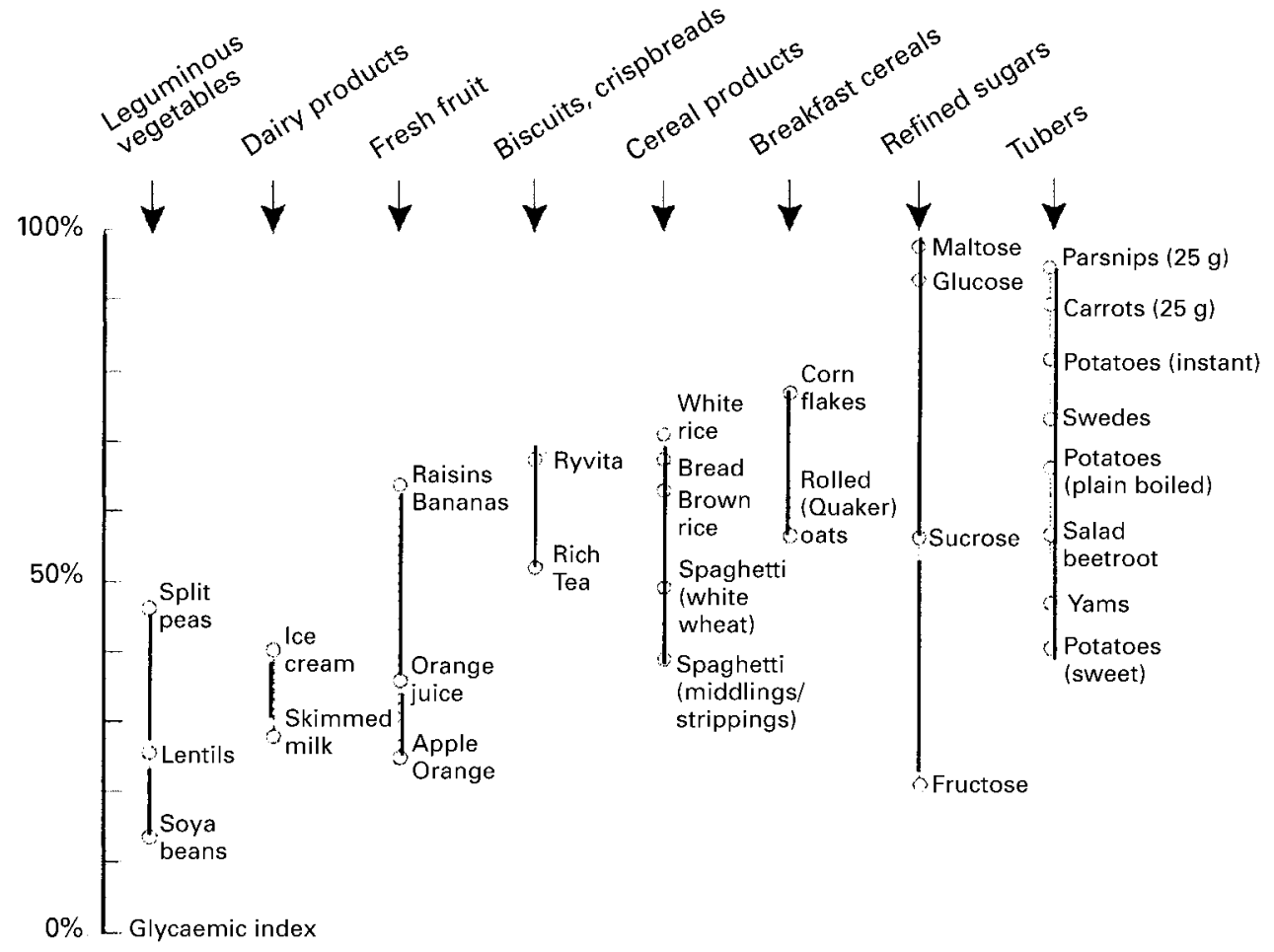

Fig. 2. Glycaemic index of several foods and food categories (from Bornet et al. 1997).

been discussed in several reviews (Miller, 1994). Diabetes mellitus is defined by elevated circulating glucose concentrations that are associated with an increased risk of developing vascular complications. The contribution of post-prandial blood glucose to the abnormal hyperglycaemia (blood glucose excursions over physiological values) can be evaluated between 20 and $40 \%$ (Slama, 2000). In an experiment, the glycaemia of sixty type 2 diabetic patients and twelve healthy control subjects was followed over the waking hours (from 08.00 hours to 24.00 hours). The post-prandial blood glucose excursions in the diabetics clearly exceeded the responses in healthy volunteers. Over the whole study period, the excessive glucose in the post-prandial period represented $38 \%$ of the supra-physiological response observed in diabetic patients, and the total duration of excessive hyperglycaemia was $13 \mathrm{~h} 28 \mathrm{~min}$.

Glycosylated haemoglobin $\left(\mathrm{Hb} \mathrm{A}_{1 \mathrm{c}}\right)$ is a crucial parameter, a function of both fasting blood glucose and post-prandial blood glucose levels. Diabetic patients have

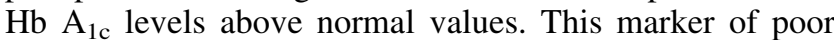
glycaemic control is a correlate of the complications of diabetes. When a patient has a level of $\mathrm{Hb} \mathrm{A}_{1 \mathrm{c}}$ equal to $8 \%$, instead of the normal value of $6 \%$, then it is important to help the patient improve glycaemic control and reduce the $\mathrm{Hb} \mathrm{A}_{1 \mathrm{c}}$ level. If $\mathrm{Hb} \mathrm{A}_{1 \mathrm{c}}$ can be decreased by only $0.5 \%$, then this represents a $25 \%$ improvement compared to the initial situation; if the $\mathrm{Hb} \mathrm{A}_{1 \mathrm{c}}$ level is decreased by $1 \%$, then the improvement represents $50 \%$ over the starting point. These changes constitute important goals in the treatment of diabetes and should be pursued.

A meta-analysis of eleven studies (carried out between 1987 and 1992) published in 1994 (Brand-Miller, 1994) lists the following improvements after a low-GI diet: a $16 \%$ decrease in mean blood glucose levels, a $20 \%$ decrease in urinary C-peptide, a $9 \%$ fall of $\mathrm{Hb} \mathrm{A}_{1 \mathrm{c}}$, a $6 \%$ decline of total cholesterol, and a $9 \%$ fall in triacylglycerols. A low glycaemic index diet also improves fibrinolytic activity (Ceriello et al. 1989; Jarvi et al. 1999) and the generation of oxidative stress (Ceriello et al. 1998) in NIDDM. As a consequence, all means to improve post-prandial blood glucose levels should be included in the treatment of diabetic patients. Although several pharmacological agents, both specific (e.g. $\alpha$-glucosidase inhibitors, glinides, humalog, nasal or pulmonary insulin, glucagon-like peptide-1 (GLP-1), Amylin, etc.) and non-specific (e.g. sulphonyl urea, metformin, thiazolidinediones, long-acting insulins, etc.) can be used, the dietetic aspects of treatment should be strongly advocated, and particularly the selection of low-GI CHO, spreading $\mathrm{CHO}$ intake over the waking hours, selecting foods with high dietary fibre, etc. The low-GI diet offers a particularly flexible and efficient solution to dietary management of the post-prandial blood glucose response.

The selection of low-GI foods allows efficient control of post-prandial insulin and glucose excursions. As opposed to high-GI foods, low-GI items induce only moderate or low glucose elevations after intake, which, in turn, elicit minor regulatory insulin output. The large increases in glycaemia observed after consumption of high-GI foods are often followed by a subsequent decrease in glycaemia values below baseline. After intake of low-GI foods, in contrast, the moderate elevations in blood glucose are followed by a slow return to baseline values, without any sign of hypoglycaemia. The sustained glycaemia levels after intake of low-GI foods could be the origin of positive 
effects on satiety, mood, cognitive performance and vigilance reported in both diabetic patients and healthy controls (Holt et al. 1992). Improving post-prandial blood glucose excursions also improves fasting blood glucose levels, although more moderately (Fontvieille et al. 1992; Wolever et al. 1992a; Jarvi et al. 1999).

The pathological pathway of type 2 diabetes mellitus includes prolonged hyperglycaemia and hyperinsulinaemia, according to the hyperglycaemia-pancreatic exhaustion hypothesis. Then the physiological impact of foods on post-ingestive glucose and insulin levels should be integrated in prevention and treatment strategies. While earlier strategies often included limiting $\mathrm{CHO}$ intake drastically, the deliberate selection of low-GI foods is a more modern approach to the problem.

There exists clinical evidence that dietary changes involving chronic replacement of foods with a higher GI by those with lower GI result in improved glycaemic control and reduced fasting serum lipids. Most of these studies include a randomized crossover design of two dietary periods lasting from 2 to 12 weeks. In NIDDM patients, short-term periods (2-6 weeks) of low-GI diets resulted in either a decrease in fasting plasma glucose or plasma cholesterol (Jenkins et al. 1988; Wolever et al. 1992a,b). In one of the longest studies in this area Brand et al. (1991) demonstrated that a 12-week low-GI diet produced a modest improvement in long-term glycaemic control but not plasma lipids in normolipidaemic well-controlled subjects with NIDDM. Furthermore, Jarvi et al. (1999) showed a net decrease in glucose and insulin responses throughout the day, and an improvement of lipid profile and fibrinolytic capacity, following a strictly controlled low-GI diet when compared to a high-GI diet.

\section{Low glycaemic index foods, such as pulses, and prevention of insulin resistance and type 2 diabetes}

The GI of foods has also been investigated in animal models. Animal studies allow a more stringent control of food intake and a more invasive exploration of the chain of events taking place between glycaemic and insulinaemic responses and eventual effects at the cellular and molecular levels. Experimental studies have been performed to determine the chronic effects of low-GI carbohydrate intake and to elucidate the underlying mechanisms.

A low-GI diet was found to be useful in decreasing plasma lipids in hyperlipidaemic non-diabetic subjects (Jenkins et al. 1985, 1987) and in normalizing diet-insulin responses of hyperinsulinaemic subjects (Behall \& Howe, 1995).

The effects of a low-GI diet have also been investigated in healthy young men. Jenkins et al. (1987) demonstrated that 2 weeks of a low-GI diet induced a decrease in fructosamine, $12 \mathrm{~h}$ blood glucose profile, $24 \mathrm{~h}$ urinary C-peptide and total serum cholesterol in six subjects. Kiens \& Richter (1996) demonstrated that a $30 \mathrm{~d}$ low-GI diet decreased insulin action on whole-body glucose disposal at a high, but not at a low, physiological plasma insulin concentration, measured by an euglycaemic hyperinsulinaemic clamp procedure in seven healthy young men. In aged patients with coronary heart disease, low-GI diet was found to improve insulin sensitivity in vivo, during an oral glucose tolerance test, and in vitro in isolated adipocytes (Frost et al. 1996).

The metabolic syndrome is a cluster of metabolic and cardiovascular risk factors associated with altered postprandial metabolism. The beneficial effects of low-GI foods on post-prandial metabolism might be useful not only for the treatment, but also for the prevention, of this condition. The clusters of risk factors that make up the insulin resistance syndrome are established risk factors for CHD (Frost et al. 1998a). Hyperinsulinaemia itself is an independent risk factor for CHD. Means of manipulating insulin sensitivity include exercise, weight loss, drug treatments and others. Since the recommended level of $\mathrm{CHO}$ intake in the diet is over $55 \%$ of total energy, it is important to investigate what effect such a high $\mathrm{CHO}$ intake will exert on insulin sensitivity. There is abundant evidence that low-GI-high-fibre diets not only affect whole-body insulin sensitivity, but also the insulin sensitivity of adipose tissue in patients with CHD and patients at risk of CHD (Frost et al. 1998a). Low-GI diets have been shown to improve both adipocyte insulin-mediated glucose uptake in vitro and insulin sensitivity in vivo, as assessed by the post-prandial fall in non-esterified fatty acid (NEFA) levels (Frost et al. 1998b). The literature suggests that a $10 \%$ fall in the GI of a diet would result in a $30 \%$ increase in insulin sensitivity. Reducing postprandial NEFA levels is important as their concentration has a rate-limiting effect on hepatic VLDL synthesis. High levels of VLDL production result in reduced HDLcholesterol and increases in the formation of atherogenic small, dense LDL. This is important since adipose tissue is responsible for the insulin resistance to glucose disposal at the muscle. Low-GI diets also reduce hepatic gluconeogenesis, suppress free-fatty-acid release and reduce postprandial hyperinsulinaemia. All these effects suggest a more insulin-sensitive environment. Epidemiological evidence supports the beneficial effects of low-GI diets on HDL-cholesterol, decreasing the risk of type 2 diabetes and CHD (Frost et al. 1999). These effects may happen through changes in insulin sensitivity.

\section{The glycaemic index in the healthy person's diet}

Nutrition experts recommend a diet that contains at least $55 \%$ of energy as $\mathrm{CHO}$ (Food and Agriculture Organization/World Health Organization, 1998) from age 2 years. It is likely that in a developed society, such a diet would include several foods of high GI (potatoes, white bread, refined cereal products, etc.) and represent a high glycaemic load (GL). This notion, in addition to that of the GI, stresses the fact that the amount of $\mathrm{CHO}$ in a food is important in determining fasting triacylglycerols (TG) and the post-prandial plasma glucose response. The GL is a measure that incorporates both the amount and the quality of dietary CHO. The GL of a specific food (the product of the food $\mathrm{CHO}$ content by its GI) serves as a basis to evaluate the total GL of the diet.

The GL has been examined in a large population of healthy women (Nurses' Health Study). In a random sample of 280 post-menopausal participants, a strong 
positive association appeared between GL and fasting TG levels (the relationship was especially marked in obese women with BMI above 25) (Liu et al. 2001). Both overall GI and total dietary $\mathrm{CHO}$ independently contributed to this effect. In the same sample, GL was inversely associated with HDL-cholesterol. It was, however, positively associated with risk of type 2 diabetes. The relative risk comparing the extreme quintiles of intake was 1.47 over 6 years of follow-up. Women with the combination of high GL and low cereal fibre intake had an even greater relative risk of type 2 diabetes ( $R R=2 \cdot 43)$. GL was also independently associated with CHD events (see below).

In a large cross-sectional study (2200 healthy adults), the GI of the diet appeared to be a greater determinant of $\mathrm{HDL}$-cholesterol than any other aspect of the diet (fat or fibre). In women, the lowest quintile for GI had $0.25 \mathrm{mmol} / \mathrm{l}$ more HDL-cholesterol than the highest quintile (Liu et al. 2000). Potentially, such a difference could lead to a $29 \%$ reduction in CHD morbidity in females. The corresponding numbers for males would predict a $7 \%$ decrease in CHD morbidity, reflecting the $0.09 \mathrm{mmol} / \mathrm{l}$ difference in HDL-cholesterol.

A prospective study carried out in a cohort of 42759 men without NIDDM or CVD clearly supported the hypothesis of a positive association between the GI of the diet and the risk of NIDDM during a 6-year followup (Salmeron et al. 1997).

The replacement of a high-GI starch (waxy cornstarch) by a low-GI starch (mung beans) for 3 weeks decreased both basal and insulin-stimulated lipogenesis in adipocytes of healthy and diabetic rats (Kabir et al. 1998b). The decrease in lipogenesis was associated with a decrease in the activity and gene expression of one of the major key enzymes implicated in lipogenesis, fatty acid synthase, in adipose tissue of controls and, to a lesser extent, of diabetic rats (Kabir et al. 1998b). These effects led to the development of small adipocytes that were more sensitive to insulin than those produced in rats fed a high-GI starch diet. Insulin-stimulated glucose oxidation (percentage of basal values) in adipocytes was increased after 3 weeks on the low-GI diet, indicating increased peripheral insulin action and glucose utilization (Kabir et al. 1998b). All these metabolic changes in adipocytes started before the detection of any change in plasma lipids, insulin or glucose at basal levels. The decrease in both plasma lipids and plasma glucose was detected after 5 weeks on a low-GI starch diet (Lerer-Metzger et al. 1996) and was always associated with smaller adipocyte size. Thus, a high-GI starch diet stimulated the enzymes implicated in lipogenesis and increased lipid synthesis, which resulted in the formation of large adipocytes; by contrast, a low-GI starch diet increased glucose oxidation and resulted in the formation of small, sensitive adipocytes. Changes in lipid metabolism at the cellular level seemed to precede any change in plasma lipids.

Whole-body insulin resistance of normal rats, as measured by an intravenous glucose tolerance test, was lower after 8 weeks on a low-GI diet (high in amylose starch) than after a high-GI diet (high in amylopectin) (Byrnes et al. 1995). High-GI diets were also found to regulate one of the main satietogenic factors, leptin. The plasma leptin levels and its expression in adipose tissue decreased in healthy rats following 12 weeks on a high-GI starch diet, as compared to a low-GI diet (Kabir et al. 2002). These changes were not accompanied by an increase in body weight, which can be detected only after 16 weeks on the high-GI diet (Pawlak et al. 2001).

\section{Low glycaemic index foods, such as pulses, and diabetes-related diseases (obesity, coronary heart disease and the metabolic syndrome)}

Changes in environmental conditions, such as the increasing availability of energy-dense, usually high-fat foods and the diminishing levels of habitual activity, appear to be responsible for the increasing prevalence of risk factors for CHD. Low-fat, high-CHO diets are recommended to prevent weight gain in normal-weight individuals and promote weight loss in the obese. The diets, however, may be as energy-dense as high-fat foods because of the high CHO content. It has also been argued that low-fat foods may decrease HDL-cholesterol and increase triacylglycerols in the blood, and therefore have a negative effect on cardiovascular risk.

In the Health Professional Follow-up Study of 244 middle-aged women, the glycaemic load was independently associated with CHD events after adjustment for age, smoking, total energy intake and other CHD risk factors. CHD was better predicted by the GI than by the typical measures of total, simple or complex $\mathrm{CHO}$ in the diet (Liu et al. 2000). The adverse effects of a high-GI diet were most obvious in women with a BMI above 23 .

A study examined whether high dietary GI was associated with hyperinsulinaemia, hyperglycaemia, dyslipidaemia and CHD risk in elderly men (van Dam et al. 2000). Men aged 64-84 years $(n=646)$, without a history of CHD or diabetes, were followed prospectively between 1985 and 1995 for incidence of major CHD (non-fatal myocardial infarction or death due to CHD). The overall GI and GL were assessed in this population using the cross-check dietary history method. A glycaemic load score was computed for each participant. The average GI in this population, with white bread as the reference, was 82. The GI was inversely correlated with fibre, fruit and milk intake, while it was directly related to intake of white bread and sugar products. The GL was more strongly correlated with overall $\mathrm{CHO}$ intake than with the GI. Individual GI was not appreciably associated with blood concentrations of total cholesterol, HDL-cholesterol, triacylglycerols, or insulin and glucose. During 4572 person-years of follow-up, 94 cases of CHD were documented. The risk ratio for CHD was 1.11 for the highest, compared to the lowest, tertile of GI. The GL was not associated with CHD risk.

Obesity is a severe public health problem in all industrialized countries, as well as in developing ones. The prevalence is extremely high in adults (in certain countries, $50 \%$ of adults are overweight). In children, the prevalence of obesity, and particularly massive obesity, is increasing rapidly. Dietary factors seem to play a crucial role in this trend, along with other aspects of life-style (inactivity). Body weight reducing programmes generally encourage a 
low-fat diet. The recommended CHO-rich, and fibre-rich diet can induce weight loss in overweight persons, when it is continued over weeks or months.

A novel approach to the obesity problem may involve reductions in dietary GI (Ludwig, 2000). Acute feeding studies have shown that the rate of $\mathrm{CHO}$ absorption after a meal is inversely proportional to satiety and directly related to voluntary energy intake in the post-prandial period. A recent study explored the hormonal and metabolic changes that occur after consumption of isoenergetic meals differing in GI. Obese teenage boys participated in three test meals of low, medium or high GI (Ludwig et al. 1999). They ate $53 \%$ more energy in the $5 \mathrm{~h}$ after the high-GI meal compared to the medium-GI meal, and $81 \%$ more energy after the high-GI meal compared to the low-GI meal. The changes in energy intake were associated with different metabolic profiles: blood glucose and fatty acid concentrations were low, while counterregulatory hormones were elevated $3-5 \mathrm{~h}$ following the high-GI meal compared to the low-GI meal. This study suggests that the metabolic consequences of a high-GI meal limit the availability of metabolic fuels in the postabsorptive period and stimulate overeating.

The effects of energy-restricted low- and high-GI diets were investigated in an in-patient crossover study lasting 1 week (Agus et al. 2000). Overweight to moderately obese young men with stable body weight for the previous 6 months participated in this study. Following a $2 \mathrm{~d}$ period of baseline observation of their spontaneous diets, the subjects were fed either high- or low-GI diets containing $50 \%$ of estimated total energy requirements for $6 \mathrm{~d}$. Resting energy expenditure was significantly lower in young obese men following the high- compared to the low-GI diet $(7.38$ versus $7.78 \mathrm{MJ} / \mathrm{d})$. In addition, nitrogen balance tended to be more negative on the high- compared to the low-GI diet $(-9.7$ versus $+25.7 \mathrm{mg} \mathrm{N} / \mathrm{kg}$ per d). These observations suggest that the physiological adaptations to energy restriction can be modified, and that low-GI diets could be better tolerated in the long term.

Body weight decreased more over 12 weeks in 15 obese female subjects when the prescribed diet was low GI compared to high GI, while fasting insulin levels decreased more on the low-GI diet (Slabber et al. 1994). The dietary prescription was controlled for total energy and macronutrient content. Obese children lost more weight on an ad libitum low-GL diet than patients assigned to an energyrestricted low-fat diet. These studies suggest a role for the GI in the control of food intake and body weight.

The chronic use of low-GI diets could exert effects on glucose and lipid metabolism, as well as on body fat distribution. In a double-blind crossover study of 11 healthy, overweight men, 5 weeks on a low-GI diet improved several metabolic and dietary parameters, as compared to 5 weeks on a high-GI diet (Bouché et al. 2000). While total energy and macronutrient intake were the same under both conditions, the fibre content of the low-GI diet was higher. Body weight was not affected by the two diets, but the total fat body mass, as measured using the dual-energy X-ray absorbiometry (DEXA) method, decreased by $500 \mathrm{~g}$ more on the low- than on the high-GI diet. The loss in body fat was most marked in the abdominal region and was accompanied by several favourable gene expression parameters (obesity gene, Ob; lipoprotein lipase, LPL; hormone-sensitive lipase, HSL). In addition, fasting total plasma cholesterol tended to be lower after 5 weeks on the low-GI diet, and the triacylglycerol area under the curve after lunch was lower during the low-GI diet than during the high-GI diet. These observations suggest that low-GI diets could be beneficial in healthy overweight persons and could help in the prevention of metabolic disorders.

\section{Conclusions}

In affluent societies, excess energy intake aggravated by physical inactivity is associated with an increasing prevalence of obesity, type 2 diabetes mellitus and CVD. Excessive fat consumption is widely believed to be a major contributing factor in these disorders. As a consequence, several public health organizations (for example, the American Diabetes Association, 1997) recommend a low-fat diet in the prevention and treatment of obesity and diabetes. A potential adverse consequence of these recommendations is an actual decrease in fat intake accompanied with a concomitant increase in dietary $\mathrm{CHO}$, thus increasing the GL and potentially the overall GI of the diet. Selecting low-GI foods is important in people who achieve a significant decrease in dietary lipids.

Low-GI diets have been shown to reduce fasting and post-prandial insulin, glucose, triacylglycerol and nonesterified fatty acid concentrations. In addition, these diets increase HDL-cholesterol and decrease total cholesterol, while improving in vivo and in vitro insulin-mediated glucose uptake. Prospective studies have demonstrated that low-GI CHO improves insulin sensitivity in subjects with diabetes, obesity and CHD, as well as those at risk of CHD. Intervention studies have shown that VLDL concentrations are lowered. Low-GI diets are thus associated with a wide range of benefits with respect to established metabolic risk factors.

The selection of low-GI foods has been advocated in the healthy eating guidelines for people with diabetes in Australia and New Zealand (International Diabetes Institute, 1994). The last European dietary recommendations (Diabetes and Nutrition Study Group of the European Association for the Study of Diabetes, 1995) for patients with type 2 diabetes suggested that most of dietary energy intake should come from a combination of carbohydrates and monounsaturated fatty acids, with a special emphasis on carbohydrates with low GI. Recently, the low-GI diet was also recommended in healthy individuals by the joint Food and Agriculture Organization and World Health Organization Expert Consultation (1998).

\section{References}

Agus MSD, Swain JF, Larson CL, Eckert EA \& Ludwig DS (2000) Dietary composition and the physiologic adaptations to energy restriction. American Journal of Clinical Nutrition 71, 901-907.

American Diabetes Association (1997) Nutrition recommendations 
and principles for people with diabetes mellitus (Position Statement). Diabetes Care 20, 514-517.

Behall K \& Howe J (1995) Effect of long-term consumption of amylose vs amylopectin starch on metabolic variables in human subjects. American Journal of Clinical Nutrition 61, 334-340.

Bornet FR, Billaux MS \& Messing B (1997) Glycaemic index concept and metabolic diseases. International Journal of Biology Macromolecules 21, 207-219.

Bornet FR, Cloarec D, Barry JL, Colonna P, Gouilloud S, Laval JD \& Galmiche JP (1990) Pasta cooking time: influence on starch digestion and plasma glucose and insulin responses in healthy subjects. American Journal of Clinical Nutrition 51, 421-427.

Bornet FR, Costagliola D, Rizkalla SW, Blayo A, Fontvieille AM, Haard MJ, Letanoux M, Tchobroutsky G \& Slama G (1987) Insulinemic and glycemic indexes of six starch-rich foods taken alone and in a mixed meal by type 2 diabetics. American Journal of Clinical Nutrition 45, 588-595.

Bornet FR, Fontvieille AM, Rizkalla S, Colonna P, Blayo A, Mercier C \& Slama G (1989) Insulin and glycemic responses in healthy humans to native starches processed in different ways: correlation with in vitro alpha-amylase hydrolysis. American Journal of Clinical Nutrition 50, 315-323.

Bouché C, Rizkalla SW, Luo J, Veronese A \& Slama G (2000) Regulation of lipid metabolism and fat mass distribution by chronic low glycemic index diet in non diabetic subjects. Diabetes 49, A40 (Abstract 165-OR).

Brand JC, Colagiuri S, Crossman S, Allen A, Roberts DC \& Truswell AS (1991) Low-glycemic index foods improve longterm glycemic control in NIDDM. Diabetes Care 14, 95-101.

Brand-Miller JC (1994) Importance of glycemic index in diabetes. American Journal of Clinical Nutrition 59, 747S-752S.

Buyken AE, Toeller M, Heitkamp G, Karamanos B, Rottiers R, Muggeo M \& Fuller JH (2001) Glycemic index in the diet of European outpatient with type 1 diabetes: relationship of hemoglobin and serum lipids. American Journal of Clinical Nutrition 73, 574-581.

Byrnes S, Brand-Miller J \& Denyer G (1995) Amylopectin starch promotes the development of insulin resistance in rats. Journal of Nutrition 125, 1430-1437.

Calle-Pascual A, Gomez VEL \& Bordiu E (1988) Foods with a low glycemic index do not improve glycemic control of both type 1 and type 2 diabetic patients after one month of therapy. Diabète et Metabolisme 14, 629-633.

Ceriello A, Bortolotti N, Motz E, Crescentini A, Lizzio S, Russo A, Tonutti L \& Taboga C (1998) Meal-generated oxidative stress in type 2 diabetic patients. Diabetes Care 21, 1529-1533.

Ceriello A, Giugliano D, Quatraro A, Dello Russo P, Marchi E \& Torella R (1989) Hyperglycemia may determine fibrinopeptide A plasma level increase in humans. Metabolism 38, 1162-1163.

Crapo P, Reaven G \& Olefsky J (1977) Postprandial plasma glucose and insulin responses to different complex carbohydrates. Diabetes 26, 1178-1183.

Diabetes and Nutrition Study Group of the European Association for the Study of Diabetes (1995) Recommendations for the nutritional management of patients with diabetes mellitus. Diabetes Nutrition and Metabolism 8, 1-4.

Feskens E \& Kromhout D (1989) Cardiovascular risk factors and the 25-year incidence of diabetes mellitus in middle-aged men: the Zutphen Study. American Journal of Epidemiology 130, $1101-1108$.

Fontvieille A, Acosta M, Rizkalla S, Bornet F, David P, Letanoux M, Tchobroutsky G \& Slama G (1988) A moderate switch from high to low glycemic index foods for 3 weeks improves the metabolic control of type 1 (IDDM) diabetic subjects. Diabetes Nutrition and Metabolism 1, 139-143.
Fontvieille A, Rizkalla S, Penfornis A, Acosta M, Bornet F \& Slama G (1992) The use of low glycemic index foods improves metabolic control of diabetic patients over five weeks. Diabetic Medicine 9, 1-7.

Food and Agriculture Organization/World Health Organization (1998) Carbohydrates in human nutrition. Report of a joint FAO/World Health Organization Expert Consultation. FAO Food and Nutrition Paper 66, 1-140.

Foster-Powell K \& Brand-Miller JB (1995) International tables of glycemic index. American Journal of Clinical Nutrition 62, 871S-890S.

Foster-Powell K, Holt SH \& Brand-Miller JB (2002) International tables of glycemic index and glycemic load values: 2002. American Journal of Clinical Nutrition 76, 5-56.

Frost G, Keogh B, Smith D, Akisanya K \& Leeds A (1996) The effect of low-glycemic carbohydrate on insulin and glucose response in vivo and in vitro in patients with coronary heart disease. Metabolism 45, 669-672.

Frost G, Keogh B, Smith D, Leeds AR \& Dornhorst A (1998b) Reduced adipocyte insulin sensitivity in Caucasian and Asian subjects with coronary heart disease. Diabetes Medicine 15, 1003-1009.

Frost G, Leeds AA, Dore CJ, Madeiros S, Brading S \& Dornhorst A (1999) Glycaemic index as a determinant of serum HDLcholesterol concentration. Lancet 353, 1045-1048.

Frost G, Leeds A, Trew G, Margara R \& Dornhorst A (1998a) Insulin sensitivity in women at risk of coronary heart disease and the effect of a low glycaemic index diet. Metabolism 47, $1245-1251$.

Holt S, Brand J, Soveny C \& Hansky J (1992) Relationship of satiety to postprandial glycaemic, insulin, and cholecystokinin responses. Appetite 18, 129-141.

International Diabetes Institute (1994) Diabetes, Eating For Health. Melbourne: International Diabetes Institute.

Jarvi AE, Karlstrom BE, Granfeldt YE, Björck IME, Asp NG \& Vessby BO (1999) Improved glycemic control and lipid profile and normalized fibrinolytic activity on a low-glycemic index diet in type 2 diabetic patients. Diabetes Care 22, 10-18.

Jenkins DJ, Leeds AE, Gassull MA, Cochet B \& Alberti GM (1977) Decrease in postprandial insulin and glucose concentrations by guar and pectin. Annals of Internal Medicine 86, 20-23.

Jenkins DJ, Wolever TM, Buckley G, Lam K, Giudici S, Kalmusky J, Jenkins A, Patten R, Bird J, Wong G \& Josse R (1988) Low glycemic-index starchy foods in the diabetic diet. American Journal of Clinical Nutrition 48, 248-254.

Jenkins DJ, Wolever TM, Jenkins AL, Thorne MJ, Lee R, Kalmusky J, Reichert R \& Wong GS (1983) The glycemic index of food tested in diabetic patients. A new basis for carbohydrate exchange favouring the use of legumes. Diabetologia 24, 257-264.

Jenkins D, Wolever T, Kalmusky J, Giudici S, Giordano C, Patten R, Wong G, Bird J, Hall M, Buckley G \& Csima A (1985) Low glycemic index carbohydrate foods in the management of hyperlipidemia. American Journal of Clinical Nutrition 42, 604-617.

Jenkins D, Wolever T, Kalmusky J, Giudici S, Giordano C, Patten R, Wong G, Bird J, Hall M, Buckley G \& Csima A (1987) Low glycemic index diet in hyperlipidemia: use of traditional starchy foods. American Journal of Clinical Nutrition 46, 66-71.

Jenkins D, Wolever T, Taylor H, Barker H, Fielden H, Baldwin JM, Bowling AC, Newman HC, Jenkins AL \& Goff DV (1981a) Glycemic index of foods. A physiological basis for carbohydrate exchange. American Journal of Clinical Nutrition 34, 362-366.

Jenkins DJ, Wolever TM, Taylor RH, Barker HM, Fielden H \& Jenkins AL (1981b) Effect of guar crispbread with cereal products and leguminous seeds on blood glucose concentrations of diabetics. British Medical Journal 281, 1248-1250. 
Kabir M, Rizkalla S, Champ M, Luo J, Boillot J, Bruzzo F \& Slama G (1998a) Dietary amylose-amylopectin starch content affects glucose and lipid metabolism in adipocytes of normal and diabetic rats. Journal of Nutrition 128, 35-43.

Kabir M, Rizkalla S, Guerre-Millo M, Laromigiere M \& Slama G (2002) Negative regulation of leptin by chronic high glycemic index starch diet. Metabolism 49, 764-769.

Kabir M, Rizkalla S, Quignard-Boulangé A, Guerre-Millo M, Boillot J, Ardoin B, Luo J \& Slama G (1998b) A high glycemic index starch diet affects lipid storage-related enzymes in normal and to a lesser extent in diabetic rats. Journal of Nutrition 128, 1878-1883.

Kiens B \& Richter E (1996) Types of carbohydrate in an ordinary diet affect insulin action and muscle substrates in humans. American Journal of Clinical Nutrition 63, 47-53.

Lafrance L, Rabasa-Lhoret R, Poisson D, Ducros F \& Chiasson J (1998) Effects of different glycaemic index foods and dietary fibre intake on glycaemic control in type 1 diabetic patients on intensive insulin therapy. Diabetic Medicine 15, 972-978.

Lang V, Bornet FR, Vaugelade P, van Ypersele de Strihou M, Luo J, Pacher N, Rossi F, La Droitte P, Duée PH \& Slama G (1999) Euglycemic hyperinsulinemic clamp to assess posthepatic glucose appearance after carbohydrate loading. 2. Evaluation of corn and mung bean starches in healthy men. American Journal of Clinical Nutrition 69, 1183-1188.

Lerer-Metzger M, Rizkalla S, Luo J, Champ M, Kabir M, Bruzzo F, Bornet F \& Slama G (1996) Effect of long-term low-glycemic index starchy food on plasma glucose and lipid concentrations and adipose tissue cellularity in normal and diabetic rats. British Journal of Nutrition 75, 723-732.

Liu S, Manson JE, Stampfer MJ, Holmes MD, Hu FB, Hankinson SE \& Willett WC (2001) Dietary glycemic load assessed by food-frequency questionnaire in relation to plasma highdensity-lipoprotein cholesterol and fasting plasma triglycerides in postmenopausal women. American Journal of Clinical Nutrition 73, 560-566.

Liu S, Willett WC, Stampfer MJ, Hu F, Franz M, Sampson L, Hennekens CH \& Manson JE (2000) A prospective study of dietary glycemic load, carbohydrate intake and risk of coronary heart disease in US women. American Journal of Clinical Nutrition 71, 1455-1461.

Ludwig DA (2000) Dietary glycemic index and obesity. Journal of Nutrition 130, 280S-283S.

Ludwig DA, Majzoub JA, Al-Zahrani A, Dallai G, Blanco I \& Roberts SB (1999) High glycemic index foods, overeating, and obesity. Pediatrics 103, e261-e266.
Miller JC (1994) Importance of glycemic index in diabetes. American Journal of Clinical Nutrition 59, Suppl., 747S-752S.

Pawlak DB, Bryson JM, Denyer GS \& Brand-Miller JC (2001) High glycemic index starch promotes hypersecretion of insulin and higher body fat in rats without affecting insulin sensitivity. Journal of Nutrition 131, 99-104.

Salmeron J, Ascherio A, Rimm E, Colditz G, Spiegelman D, Jenkins D, Stampfen M, Wing A \& Willett W (1997) Dietary fiber, glycemic load, and risk of NIDDM in men. Diabetes Care 20, 545-550.

Slabber M, Barnard HC, Kuyl JM, Dannhauser A \& Schall R (1994) Effects of a low-insulin-response, energy-restricted diet on weight loss and plasma insulin concentrations in hyperinsulinemic obese females. American Journal of Clinical Nutrition 60, 48-53.

Slama G (2000) Clinical significance of post-prandial blood glucose excursions in type 1 and type 2 diabetes mellitus. International Journal of Clinical Practice 112, Suppl., 9-12.

Spaethe R, Brinck UC, Sabin J, Wubbens K \& Otto H (1972) Exchange of carbohydrates, following the principle of biological equivalents, in the diabetic diet. Journées Annuelles de Diabétologie de l'Hôtel-Dieu 13, 253-259.

Thorne MJ, Thompson LU \& Jenkins DJA (1983) Factors affecting starch digestibility and the glycemic response with special reference to legumes. American Journal of Clinical Nutrition 38, 481-488.

Toeller M, Klischan A, Heitkamp G, Schumacher W, Milne R, Buyken A, Karamanos B \& Gries FA (1996) Nutritional intake of 2868 IDDM patients from 30 centres in Europe. Diabetologia 39, 929-939.

van Dam RM, Visscher AW, Feskens EJ, Verhoef P \& Kromhout D (2000) Dietary glycemic index in relation to metabolic risk factors and incidence of coronary heart disease: the Zutphen Elderly study. European Journal of Clinical Nutrition 54, 726-731.

Wolever TMS, Jenkins DJA, Jenkins AL \& Josse RG (1991) The glycemic index: methodology and clinical implications. American Journal of Clinical Nutrition 54, 846-854.

Wolever T, Jenkins D, Vuksan V, Jenkins A, Buckley G, Wong G \& Josse R (1992a) Beneficial effect of low glycemic index diet in type 2 diabetes. Diabetic Medicine 9, 451-458.

Wolever T, Jenkins D, Vuskan V, Jenkins A, Wong G \& Josse R (1992b) Beneficial effect of low-glycemic index diet in overweight NIDDM subjects. Diabetes Care 15, 562-564. 